\title{
What is New in the "New Rural Co-operative Medical System"? An Assessment in One Kazak County of the Xinjiang Uyghur Autonomous Region*
}

Sascha Klotzbücher, Peter Lässig, Qin Jiangmei and Susanne Weigelin-Schwiedrzik

\begin{abstract}
In 2002, the Chinese leadership announced a change in national welfare policy: Voluntary medical schemes at county level, called the "New Rural Co-operative Medical System" should cover all counties by 2010. This article addresses the main characteristics of this system, analyses the introduction of local schemes based on our own field studies in one Kazak county of the Xinjiang Uyghur Autonomous Region since 2006, and argues that the fast progressing of the local scheme and the flexibility shown by local administrators in considering structural and procedural adjustments are not the result of central directives but of local initiatives. Recentralization from the township governments to functional departments in the provincial and the central state administration is only one aspect of current rural governance. Complementary forms of locally embedded responsiveness to the needs of health care recipients are crucial in restructuring the administration and discharge of health care. These new modes of governance are different from the hierarchical control and institutionalized representation of interests of the local population.
\end{abstract}

In 2002, the Chinese leadership announced a change in national welfare policy. Local voluntary medical schemes at the county level, presented as the "New Rural Co-operative Medical System"' (NRCMS) (xinxing nongcun hezuo yiliao $z h i d u$ 新型农村合作医疗制度) were scheduled to cover all counties by the year

* Financial support has come from the Austrian Science Fund (FWF) and the Eurasia Pacific Uninet. The authors would like to thank Rui Dongsheng and eight Kazak graduate students for conducting the health survey in 2006 and all interviewees.

1 NRCMS definition in 2003: "[It] provides mutual help and benefit, mainly focusing on and curing heavy diseases. It is organized, led and supported by the government and with voluntary participation of the farmers. The system is financed jointly by individuals, collectives and government," "Guanyu jianli xinxing hezuo yiliao zhidu yijian" ("Opinions about the introduction of NRCMS"), Guobanfa, No. 3 (16 January 2003), http://www.jswst.gov.cn/dfnewsdisplay.php?newsid=436, accessed 13 May 2006. 
2010 and have been implemented since 2004. For the first time in history, these local schemes, now managed at the county level, are subsidized directly from the central state budget in the regions of Western and Central China. ${ }^{2}$ After years of waiting for local initiatives to find a solution for rural health care, the central government has come to realize that it needs to compromise with rural society in a way which recognizes that state intervention is not identical with state dominance and allows for local initiatives.

This article discusses the main policy changes and analyses the introduction of the NRCMS scheme, ${ }^{3}$ using policy documents and data from field studies in Xinyuan county, Yili Kazak Autonomous Prefecture, Xinjiang Uyghur Autonomous Region (Xinjiang UAR) collected in 2006 and 2007. ${ }^{4}$ The existing discussion of modes of rural governance is narrow in scope. Authors analyse policy fields using a set of tools focusing on three dimensions of policy. In the policy and politics dimension analysis focuses on extractive state capacity using forms of governance which rely on rigid implementation and evaluation of Party cadres. In the polity dimension the analysis focuses on centralized and hierarchical, institutionalized forms of coercion. ${ }^{5}$ Other approaches focus on "rightful resistance" or democratic participation based on rights defined by the central government. ${ }^{6}$ This article discusses examples from transformative and distributive policy fields where voluntary enrolment dominates instead of coercion. Despite intervention from

2 "Zhonggong zhongyang guowuyuan guanyu jin yibu jiaqiang nongcun weisheng gongzuo de jueding" ("Decision of the Central Committee of the CP and the State Council to strengthen health work in rural areas"), Zhongfa, No. 13 (30 October 2002), http://www.agri.gov.cn/zcfg/t20021107_22649.htm, accessed 3 April 2003. This policy was expanded to other regions in 2006. "Guanyu jiakuai tuijin xinxing nongcun hezuo yiliao shidian gongzuo de tongzhi" ("Circular about speeding up the introduction of pilots of NRCMS"), Weinongweifa, No. 13 (19 January 2006), http://www.moh.gov.cn/public/open. aspx?n_id=11283, accessed 12 May 2006.

3 See the following regarding the Co-operative Medical System before 2002: Liu Yuanli, Keqin Rao and Shanlian $\mathrm{Hu}$, People's Republic of China. Toward Establishing a Rural Health Protection System (Manila: Asian Developing Bank, 2002), http://www.adb.org/documents/reports/ RC_rural_health_protection_system/prc_rural_health.pdf, accessed 26 November 2004; Sascha Klotzbücher, Das ländliche Gesundheitswesen der VR China. Strukturen - Akteure - Dynamik (Frankfurt am Main: Peter Lang, 2006). Regarding the NRCMS see Weisheng tongji xinxi zhongxin, Zhongguo xinxing nongcun hezuo yiliao jinzhan jiqi xiaoguo yanjiu (Research on Development and Effectiveness of China's New Rural Co-operative Medical Scheme) (Beijing: Zhongguo xiehe yiyuan daxue chubanshe, 2007); Liu Yuanli, "Development of the rural health insurance system in rural China," Health Policy and Planning, Vol. 19, No. 3 (2004), pp. 159-65. Jane Duckett, "Local governance, health financing, and changing patterns of inequality in access to health care," in Vivienne Shue and Christine Wong (eds), Paying for Progress in China: Public Finance, Human Welfare and Changing Patterns of Inequality (London: Routledge, 2007), pp. 46-68; Wang Hong, Zhang Licheng, Winnie Yip and William Hsiao, "Adverse selection in a voluntary rural mutual health care health insurance scheme in China," Social Science \& Medicine, Vol. 63, No. 5 (2006), pp. 1236-45; Sukhan Jackson, Adrian C. Sleigh, Li Peng and Liu Xi-li, "Health finance in rural Henan: low premium insurance compared to the out-of-pocket system," The China Quarterly, No. 181 (2005), pp. 137-52.

4 This article does not discuss the minority population aspects, and how they might affect the "responsiveness" of the administrators.

5 See Oliver Treib, Holger Bähr and Gerda Falkner, "Modes of governance: towards a conceptual clarification," Journal of European Public Policy, Vol. 14, No. 1 (2007), pp. 1-20 at pp. 5-11. An example is Yang Dali, Remaking the Chinese Leviathan: Market Transition and the Politics of Governance in China (Stanford: Stanford University Press, 2004).

6 Kevin O'Brien and Li Lianjiang, Rightful Resistance in Rural China (Cambridge: Cambridge University Press, 2006). 
central government and a clear formulation of forms and level of reimbursement, the decision space ${ }^{7}$ for local actors in the field of welfare policy is much bigger than estimated in such national campaigns. Governance goes beyond hierarchical "command and control" and finds new modes for higher accountability of local cadres.

We argue that one crucial and new factor in this form of governance is "responsiveness." As a locally embedded mechanism of multi-level governance, it improves the relationship between different levels of state agencies, health providers and patients and tries to overcome the distance between state and society. ${ }^{8}$ Responsiveness is a market-based mechanism which integrates the perception and behaviour of stakeholders into the running of the scheme avoiding both coercion and participatory formalisms. Responsiveness can be defined as the outcome of re-designing institutions and procedures in such a way that they respond appropriately to the expectations of targeted individuals. ${ }^{9}$ As a result of compliance with government regulations and individual expectations, responsiveness reacts to the feedback of stakeholders in a non-formalized way. ${ }^{10}$

\section{Characteristics of NRCMS}

Besides providing subsidies based on the number of actual participants, the central state agencies defined several objectives and procedures for NRCMS. The three main objectives are as follows.

First, reduce illness-induced poverty. In the year 2001, NRCMS was declared a “non-compulsory” policy (bushi qiangzhixing 不是强制性). ${ }^{11}$ This situation changed after 2002. The Ministry of Health took the lead by introducing the scheme as compulsory. A consensus was reached that individual contributions to NRCMS "should not be regarded as an increase of the peasants' financial

7 See Thomas Bossert, "Analyzing the decentralization of health systems in developing countries: decision space, innovation and performance," Social Science and Medicine, Vol. 47, No. 10 (1998), pp. 1513-27.

8 Susanne Weigelin-Schwiedrzik, "The distance between state and rural society in the PRC. Reading document No. 1 (February 2004)," Journal of Environmental Management, Vol. 87, No 2 (2008), pp. 216-25.

9 Definition slightly changed, see Alma De Silva, A Framework for Measuring Responsiveness. GPE Discussion Paper Series No. 32 (no year), http://www.who.int/responsiveness/papers/paper32.pdf, accessed 6 November 2007. Responsiveness, originally developed in economic studies of the principal-agent theory, is used for the relationship between central and local state agencies (Klotzbücher, Gesundheitswesen, pp. 151, 169ff). Further, it is developed in the WHO Health 2000 report as "to assess, monitor and raise awareness of how people are treated and the environment in which they are treated when seeking health care." See World Health Organisation (WHO), Health System Responsiveness, http://www.who.int/responsiveness/en/, accessed 23 October 2007.

10 See further Sascha Klotzbücher and Peter Lässig, "Transformative state capacity in post-collective China: the introduction of the 'New Rural Cooperative Medical System (NRCMS)' in two counties of Western China, 2006-2008," European Journal of East Asian Studies, Vol. 8, No. 1 (2009), pp. 61-89. Regarding the importance of feedback loops in other policy fields, see Sebastian Heilmann, "Policy experimentation in China's economic rise," Studies in Comparative International Development, Vol. 43, No. 1 (2008), pp 1-26.

11 "Guanyu nongcun weisheng gaige yu fazhan de zhidao yijian" ("Suggestions about the reform and management in rural health care"), Guobanfa, No. 39 (8 May 2001), http://www.moh.gov.cn/newhtml/8065. htm, accessed 30 July 2007. 
burden” (buneng shiwei zengjia nongmin fudan 不能视为增加农民负担), ${ }^{12}$ and that NRCMS should be regarded as in line with the anti-poverty efforts of the Ministry of Finance. From 2002, NRCMS turned into a key measure of high political priority against the "return into poverty due to [the financial costs of] illness (yin bing fan pin 因病返贫). ${ }^{13}$

Second, make participation in NRCMS voluntary. Because of regional differences with respect to economic, social and cultural conditions and variations in pre-existing local medical schemes, ${ }^{14}$ there are inherent limits to the enforcement of health care policies in a top-down approach. Standardized premium and reimbursement levels could destabilize the secure operation of the schemes. In addition, peasants seem reluctant to participate in state initiatives as a result of bad experiences accumulated in the past. ${ }^{15}$ Obviously, policy makers are conscious of these constraints and stress the need for local options as well as the necessity to stick to voluntary participation. Since 1997 the CCP leadership has repeatedly affirmed: "Farmers can enrol or withdraw from the schemes and pay their premiums voluntarily on an annual basis" (nongmin ziyuan jiaona de hezuo yiliao fei 农民自愿缴纳的合作医疗费; nongmin ziyuan canjia 农民自愿 参加). ${ }^{16}$ As a consequence, enrolment or withdrawal function as signals of the peasants' degree of satisfaction with and trust in the scheme.

The advantages of this approach are, first, that participants can decide whether the system meets their specific needs. Their willingness to join and pay for NRCMS is vital for sustaining the scheme. In addition, voluntary participation enhances the sense of "ownership" and generally induces participants to make a more judicious use of the scheme. Furthermore, administrators must convince participants of the effectiveness and efficiency of the system and build up motivation through high quality services, while high turnover rates are signals of deficiencies in the system demanding changes in the service package.

However, there are some drawbacks. It may mainly be high-risk households with people with heavy or chronic illnesses and old age which enrol. Mobilization campaigns for annual enrolment will also involve a high cost. In addition, actuarial budgeting is made difficult by fluctuation in participation, requiring rapid changes in contribution levels and benefit policies.

The third main objective is to focus on reimbursing costs of serious illnesses. Before 2002 the scope of health services was left open to adapt to prevailing local conditions. The NRCMS, however, focuses on schemes of risk-sharing especially for major diseases. ${ }^{17}$ It provides financial help for hospitalization and should thereby prevent impoverishment. In 2004 during the introductory phase of NRCMS, three alternative models were suggested to the county

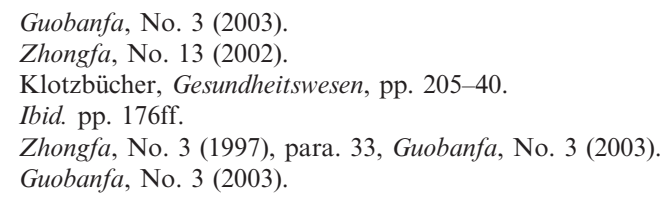


governments: separate accounts for in- and out-patient treatment; one single account, but with different reimbursement ratios for in- and out-patient treatment; or coverage only for in-patient treatment. ${ }^{18}$ The decision on which to opt for or on changes between these alternatives is at the discretion of the county.

There are two main procedural characteristics of the NRCMS. The first is a time schedule for introducing the scheme. The shift from a non-compulsory, decentralized policy to a centrally guided one with mandatory implementation can clearly be seen by the central government's time frame for implementing NRCMS. Whereas the old CMS was organized at the village, township or county level, now the counties manage NRCMS. ${ }^{19}$ In 2006, 40 per cent of all counties were to set up pilots; this would increase to 60 per cent in 2007; by 2008, every county should basically (jibenshang 基本上) have set up a NRCMS scheme; full national coverage ${ }^{20}$ is to be reached by 2010.21 Even though NRCMS must be introduced by all county administrations by 2010, individual participation remains voluntary, albeit with a high participation rate as a necessary precondition for economic and political success.

The second procedural characteristic is that transfers from the central government are earmarked as matching funds. After the promulgation of this policy change in 2002, the central budget began to subsidize NRCMS pilot schemes in all non-urban areas in Western and Central China in 2005. ${ }^{22}$ In 2006, the central government increased its contribution from 10 to 20 yuan per enrolled participant for all Western and Central regions with a rural population of more than 70 per cent, and for pilot counties in Liaoning, Jiangsu, Zhejiang, Fujian, Shandong and Guangdong. ${ }^{23}$

The state contributions are not global subsidies. They are allocated in accordance with the actual number of individual participants and earmarked for in-patient treatment. ${ }^{24}$ Subsidies are not subject to bargaining between higher and lower levels, but depend on participation rates and financial contributions of the county and provincial governments. This approach enhances the "responsiveness" of the scheme. The financial commitment of county and provincial governments is a precondition for the transfer of central matching funds. Their contributions to the insurance funds are supposed to be no less than 10 yuan

18 "Weishengbu, caizhengbu, guojia zhongyiyao guanliju guanyu wanshan xinxing nongcun hezuoyiliao buchang fang'an de zhidao yijian" ("Guiding suggestions of the $\mathrm{MoH}, \mathrm{MoF}$, and the State Administration of Traditional Chinese Medicine for the completion of the subsidy scheme for the NRCMS"), Weinongweifa, No. 235 (2007)), http://www.moh.gov.cn/newshtml/20180.htm, accessed 30 September 2007.

19 Zhongfa, No. 2 (2002).

20 Coverage (fugai) in this context means only the availability of a scheme in a county.

21 Weinongweifa, No. 13 (2006).

22 "Caizhengbu, weishengbu guanyu zhongyang caizheng zizhu zhongxibu diqu nongmin canjia xinxing hezuoyiliao zhidu buzhu zijin bofu youguan wenti de tongzhi" ("Circular of the MoF and MoH about the appropriation of sums that the central budget deems appropriate for subsidies of the enrolled peasants from Western and Central regions”), Caishe, No. 112 (25 August 2003), http://www.moh.gov. $\mathrm{cn} /$ newshtml/8353.htm, accessed 30 September 2007.

23 Weinongweifa, No. 13 (2006).

24 Guobanfa, No. 3 (2003). 
per enrolled participant. ${ }^{25}$ Beginning from 2007, the contribution of the county and provincial governments should be increased by 5 yuan. Since the central government only transfers subsidies when the peasants have actually enrolled and the local governments paid their contributions, the role of the participants is strengthened. If peasants participate, governments on all levels pay and get their share. Due to the NRCMS focus on severe illnesses, state subsidies are only made available for in-patient treatment in recognized hospitals belonging to the state health care system. They are not available for consultations, treatment and drugs prescribed on an out-patient basis. Thus, state subsidies flow exclusively back to state health providers and are an indirect subsidy of these institutions through responsive settings.

Local administrators are compelled to perform well by "responding" to the needs and perceptions of the participants and thus convincing them to participate. The central government encourages the implementation of NRCMS by providing subsidies but does not interfere with everyday decisions.

\section{Field Studies in Xinyuan County}

Xinyuan is a county in the north-western part of Xinjiang UAR near the frontier of Kazakhstan. It consists of ten townships (xiang 乡) and one town (zhen 镇), with a total population of 300,000 in 2006 and 305,800 in 2007, an increase of 2 per cent. Contrasting with this increasing overall trend is a decrease of the rural population from 187,400 in 2006 to 174,900 in 2007, a decrease of 6.7 per cent. ${ }^{26}$ Of the total population, 44 per cent are ethnic Kazaks, 39 per cent Han and 9 per cent Uyghurs. The majority of the Kazaks live under seminomadic conditions, moving some 1,090,000 cattle and sheep from pastures in the mountains to grass during the summer. ${ }^{27}$

\section{Approval as state pilot}

In 2005, the Health Bureau of the Xinjiang UAR approved the request of Xinyuan county to be selected as one of the first state pilot counties (guojiaji shidian xian 国家级试点县) for testing NRCMS in Xinjiang. The central government was not involved in this decision. ${ }^{28}$ The pilot started in January 2006 with 161,164 paid-up participants from among 187,400 registered rural inhabitants, representing a participation ratio of 86 per cent. By 2007, participation had only marginally increased to 162,723 (an increase of 1 per cent in absolute numbers). However, because of the drop in the rural population, the participation ratio had actually increased to 93 per cent, an increase of seven percentage

27 Yili hasake zizhizhou tongjiju (ed.), Yili hasake zizhizhou tongji nianjian 2006 (2006 Statistical Yearbook of the Yili Kazak Autonomous Prefecture) (Wulumuqi: Yili hasake zizhizhou tongjiju, 2006), p. 63.

28 Interview 01/07. 
points. ${ }^{29}$ Participation rates differ from township to township. In one of the townships visited, the reported coverage was only 77 per cent. ${ }^{30}$

\section{Administrative responsibility}

According to local regulations and to the principle of dual leadership (shuangchong lingdao 双重领导) 31 (for the NRCMS administrative structure see Figure 1), ${ }^{32}$ the head of the Xinyuan county health bureau, who oversees the management of the NRCMS office, receives technical guidance (yewushang de zhidao 业务上的指导) from the vertical functional superior, the chief of the Yili prefecture (zhou 州) health bureau in Yining and its NRCMS office, and administrative as well as operational supervision/leadership (lingdao 领导) from the county government. ${ }^{33}$ All positions in the health bureau, including those responsible for NRCMS, are established and financed by Xinyuan county (fenji guanli 分级管理), ${ }^{34}$ which also covers all operational costs according to a flat rate of 0.5 yuan per rural inhabitant ${ }^{35}$ through its offices for personnel allocation (renshiju 人事局) and for finances (caizhengju 财政局). This is a departure from the situation before 2002, when 5 per cent of the NRCMS budget was used for paying administrative overhead costs. ${ }^{36}$ As a reaction to peasants' fears about the administration using up "their" money, all contributions to NRCMS are now exclusively dedicated to the reimbursement of health service costs.

In 2007, the county NRCMS office employed ten staff with a payroll of 120,000 yuan, all remunerated by the county. Six staff members are responsible for claims processing and control. ${ }^{37}$ Medical costs incurred at village and township level are processed by the NRCMS offices in the health centres of the townships. The county NRCMS office only processes claims for medical expenses incurred at the county level and above. Additionally, it processes the monthly accounts of all other NRCMS offices in the county. ${ }^{38}$ The operational NRCMS programme and budget is decided upon by the county government, which supervises the performance of the NRCMS bureau head who in turn oversees the operations of the NRCMS offices in the health centres at the township level.

29 Interviews 16/07 Q/A 3 and interview 18/07.

30 Interview $05 / 07$.

31 See Andrew Mertha, "China's 'soft' centralization: shifting Tiao/Kuai authority relations," The China Quarterly, No. 184 (2005), pp. 791-810, at p. 792; Klotzbücher, Gesundheitswesen, pp. 142ff.

32 Xinyuan xian (Xinyuan County), Xinyuan xian xinxing nongmuqu hezuo yiliao shishi xice (shixing) (Concrete NRCMS Implementation Guidelines for Agricultural and Pastoral Regions in Xinyuan County) (Document, 2006); interview 14/07 para.1.

33 Interview $02 / 07$ paras. 2 and 3.1. Regarding the discussion of the relationship of the functional administrative superiors and leadership of local government, see Mertha, "China's 'soft' centralization," p. 797.

34 Zhongfa, No. 13 (2002).

35 Xinyuan County, NRCMS Implementation Guidelines 2008, para. 18.4.

36 Interview $02 / 07$ para. 3.4 .

37 Interview 16/07 Q/A 11.

38 Xinyuan County, NRCMS Implementation Guidelines 2008, art. 25-28. 
Figure 1: Administration of New Rural Co-operative Medical System (simplified)

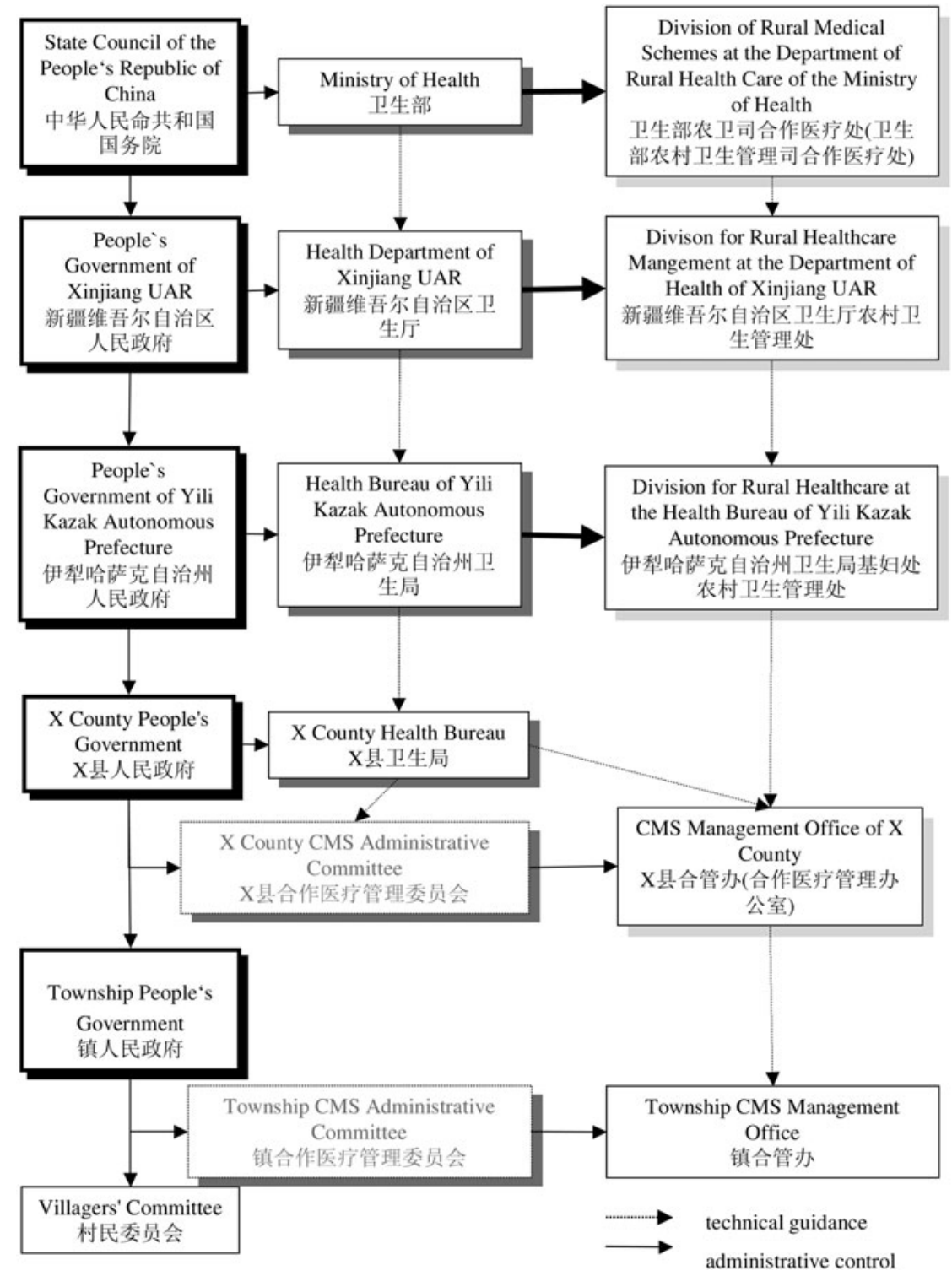

The county government guarantees the financial viability of the insurance scheme and is expected to make up any shortfall. To reduce this liability, a risk fund of 5 per cent of all state contributions is administered by Yili prefecture as fiduciary. ${ }^{39}$ 


\section{Financial contributions}

Based on the average income of the rural population, the Xinyuan county government fixed the NRCMS annual contribution from each participant at 25 yuan in 2005. This is close to the ceiling of 30 yuan established by the provincial government. ${ }^{40}$ This amount is supplemented by 10 yuan from the county government, 10 yuan from Xinjiang UAR and 20 yuan from the central government, a total of 65 yuan. The public share (central state, province and county combined) thus amounts to 61.5 per cent. New enrolments and premium collections are due every year between August and November. Thereafter, no enrolments are possible. ${ }^{41}$

Of the combined state contributions for each participant, two yuan is set aside for a reserve account, which should not exceed 10 per cent of all contributions, and 48 yuan goes into a pool account, out of which expenses for hospitalization for "major illnesses" are reimbursed. ${ }^{42}$ It should be pointed out that there is no definition of what is classed as a major disease. The contributions are pooled to provide coverage for all household members registered in the county. In accordance with the guidelines of the central state agencies, they may not be used for the reimbursement of out-patient treatment.

\section{NRCMS reimbursement levels}

Since the inception of the scheme, reimbursement levels in Xinyuan county have increased twice, while contribution rates have remained unchanged (Table 1). The deductible amount (excess) in case of hospitalization has decreased and the reimbursement ceiling increased. ${ }^{43}$

Despite government contributions and several readjustments of reimbursement rates, our own calculations for patients from "A" village have resulted in a staggering low of only 25.7 per cent of costs reimbursed between January and June 2006. ${ }^{44}$ This is explained by the fact that many surgical interventions are not covered by the scheme, ${ }^{45}$ and many farmers were unfamiliar with these and other exceptions. ${ }^{46}$

While reimbursement ceilings are higher at the higher-level institutions, the applicable excess increases and the reimbursement rates decrease the higher the

40 Interview 16/07 Q/A 4.

41 Interview 16/07 Q/A 5.

42 Guobanfa, No. 3 (2004).

43 For example, if the bill in a township hospital amounts to 1,500 yuan, the amount reimbursed according to 2007 rates will be $(1,500-80$ (excess) $)$ x $70 \%$ (reimbursement rate) $=994$ yuan or $66 \%$. Not included is that approx. $20 \%$ of the drugs or services are not reimbursable. This would lower the reimbursement rate to $53 \%$ (2007) or $37 \%$ (2006). Applying 2006 rates to the same example, the reimbursement would only have amounted to 700 yuan $(47 \%)$. All expenses above the ceiling of 8,000 yuan must be borne by the patient.

44 Interview 08/06, table.

45 See exclusion list in Xinyuan County, NRCMS Implementation Guidelines 2008, art. 23.

46 Interviews 01/07, 05/07. 
Table 1: Reimbursement Levels in Xinyuan County, 2006-2007 (yuan)

\begin{tabular}{|c|c|c|c|c|}
\hline Contribution rates & $\begin{array}{c}\text { January } 2006- \\
\text { May } 2006\end{array}$ & $\begin{array}{c}\text { June } 2006- \\
\text { December } 2006\end{array}$ & $\begin{array}{c}\text { January 2007-- } \\
\text { April } 2007\end{array}$ & $\begin{array}{c}\text { From May } \\
2007\end{array}$ \\
\hline Central government & 20 & 20 & 20 & 20 \\
\hline $\begin{array}{l}\text { Provincial } \\
\text { government }\end{array}$ & 10 & 10 & 10 & 10 \\
\hline County government & 10 & 10 & 10 & 10 \\
\hline $\begin{array}{l}\text { Individual } \\
\text { contributions }\end{array}$ & 25 & 25 & 25 & 25 \\
\hline Total & 65 & 65 & 65 & 65 \\
\hline \multicolumn{5}{|l|}{$\begin{array}{l}\text { Excess (each } \\
\quad \text { hospitalization) }\end{array}$} \\
\hline Township hospital & 100 & 100 & 100 & 80 \\
\hline County hospital & 300 & 300 & 300 & 200 \\
\hline Province hospital & 600 & 500 & 500 & 500 \\
\hline \multicolumn{5}{|l|}{ Reimbursement rates } \\
\hline Township hospital & $50 \%$ & $60 \%$ & $60 \%$ & $70 \%$ \\
\hline County hospital & $40 \%$ & $50 \%$ & $50 \%$ & $55 \%$ \\
\hline Province hospital & $30 \%$ & $40 \%$ & $40 \%$ & $40 \%$ \\
\hline \multicolumn{5}{|l|}{$\begin{array}{l}\text { Reimbursement } \\
\text { ceilings }\end{array}$} \\
\hline In-patient & 8,000 & 12,000 & 12,000 & 12,000 \\
\hline Out-patient* & 15 & 15 & 25 & 25 \\
\hline
\end{tabular}

Table 2: Percentage of Reimbursed Services and Medicamentation in Xinyuan County for In-patient Services by Hospital-level for January-June 2007 (\%)

Level of hospital

Township health centre

County hospital

Prefecture-level hospital

Region-level hospital

administrative level of the hospital (see Table 2). This is to encourage patients to seek service from the nearest possible health care institution. It also discourages them from insisting on being referred to higher-level institutions for fear of services at the township health centres not fulfilling their expectations.

Reimbursement in case of injury (as opposed to illness) is only 30 per cent. In case of hospitalization without proper medical referral, the reimbursement is reduced by ten percentage points. In case of hospitalization outside Xinyuan county, the reimbursement is reduced by ten percentage points, except for participants who live for extended periods elsewhere for reasons of work or study, or who are on authorized family visits, in which case the reduction is five percentage 
points. ${ }^{47}$ While the health facility claims directly from NRCMS for in-patient health services in township health centres or the county hospital of Xinyuan county and patients only pay the excess, when seeking treatment outside Xinyuan county patients pay first out of their own pocket and are then reimbursed upon presentation of the hospital bill at the NRCMS office of their home county. This acknowledges the increasing mobility of the rural work force and provides some relief to migrant workers who, because of often precarious contractual situations, remain uninsured at their work place. ${ }^{48}$ Participants over the age of 65 and households abiding by the family planning policy enjoy a reimbursement increase of five percentage points. This shows that NRCMS is also used to increase compliance with state policies among the rural population.

Overall, the benefits provided by NRCMS must still be considered as very modest, bearing in mind that the average annual income per capita of the population selected for the case study (Kazak pastoral households) was 2,867 yuan in 2006 (an increase of 32.3 per cent from the 2,167 yuan in 2003), ${ }^{49}$ and average out-of-pocket expenses for each case of hospitalization was 3,826 yuan. ${ }^{50}$ It is obvious that even a further increase of the current 61.5 per cent of state co-financing of the scheme will not bring a dramatic change. This is compounded by the absence of state contributions to out-patient services, which places a considerable burden on the shoulders of the rural population who are likely to fall into the poverty trap regardless of whether they are having to pay for in- or outpatient treatment.

\section{The role of local cadres}

A strict timeline set for coverage of all provinces by NRCMS (see above) does not impair its voluntary nature. Indeed, no targets for the level of participation in the local schemes appear to have been set by the central government. There is, however, evidence that mobilization targets are set by the local government. ${ }^{51}$ In Xinyuan county the level for stable operation has been set at an 80 per cent participation rate. ${ }^{52}$ Responsibility for achieving and maintaining at least this level does not lie with the administrators in the NRCMS bureau. It is also not part of their performance targets within the cadre responsibility system, and they

47 Xinyuan County, NRCMS Implementation Guidelines 2008, art. 22, and Xinyuan xian (Xinyuan County), Xinyuan xian nongmu min canjia xinjin nongmu qu hezuo yiliao xieyi shu (NRCMS Participation Agreement of Farmers and Herders in Xinyuan County) (Document 2007), para. 7.

48 Interview 05/07 para. 4.

49 Shihezi daxue, weiyena daxue (Shihezi/Vienna Universities), "Xinyuan xian muqu jumin weisheng fuwu xianzhuang ji muye yiyuan fazhan qianjing yanjiu" ("The current situation of health care service for herders in Xinyuan and the research about the development prospects for the pastoral hospitals"), unpublished, 2007, p. 66.

50 Shihezi/Vienna Universities, Xinyuan Pastoral Health Services, table 2-5-5; p. 31

51 Han Jun and Luo Dan, Zhongguo nongcun weisheng diaocha (Survey on China's Rural Medical and Health Reality) (Shanghai: Yuandong chubanshe, 2007), p. 397.

52 Interview 16/07 Q/A 8. 
receive no premiums if the 80 per cent mark has been reached or surpassed..$^{53}$ But they are evaluated according to the effective and stable management of the scheme, and stable operation is only possible with high participation rates.

The township people's governments (xiang renmin zhengfu 乡人民政府) and villagers' committees (cunmin weiyuanhui 村民委员会) are responsible for the mobilization of the population. The Party secretary responsible for health work in one township explained that he could "mobilize a team of 50 community workers and 80 village cadres" to induce peasants and herders to join NRCMS and ensure that "the enrolment percentage established by the CCP was attained." ${ }^{54}$ However, there is no evidence for a systematic coerced participation in NRCMS from any of our interviews in Xinyuan county. Reaching at least 80 per cent of coverage appears to be only a "soft" performance goal for the village and township cadres. The idea behind this seems to be that the voluntary character of NRCMS should not be jeopardized in any way.

\section{The voluntary nature of NRCMS, and fluctuation of membership}

Since participation in NRCMS is voluntary, continuing mobilization campaigns and improvements in the scheme are essential to acquire and maintain a critical level of membership. Requests to enrol may not be refused for reasons such as age or health condition. ${ }^{55}$ One inbuilt stabilizing factor to discourage adverse selection and reduce frequent opting in and out of the scheme is the requirement that persons belonging to the same household must enrol together. All persons with household registration (hukou 户口), or who have actually resided in Xinyuan county for at least five years and are not covered by any other public health insurance scheme, are eligible to join. ${ }^{56}$

The accounts are kept on a household basis. ${ }^{57}$ It is therefore essential to ascertain the household size. There are instances where only sick or elderly household members are enrolled and the healthy are not reported. Only some of the children are officially reported for household registration and consequently enrolled in the scheme upon reaching schooling age. This is particularly true for a possible second or third child. ${ }^{58}$ In order to facilitate subsequent enrolment of eligible household members, this can be done at any time without retroactive premium payments. The county registration office (huji ke 户籍科), however, will impose a penalty. ${ }^{59}$

The goal of close to full population coverage will be difficult to obtain and retain. However, judging from the reported figure of 93 per cent participation

56 Xinyuan County, NRCMS Participation Agreement, para. 7.

57 Shihezi/Vienna Universities, Xinyuan Pastoral Health Services, p. 59.

58 Interview 11/07.

59 Interview $02 / 08$. 
already for the second year of the pilot (2007), the scheme must be considered a great initial success, even more so in light of the 30 per cent dissatisfaction rate among NRCMS participants in 2006 (see below) and speculation about a drop in participation numbers. The main reasons for the continuing high participation rate in 2007 may be found in the NRCMS improvements, which were decided based on customer feedback in our household survey of herders in Xinyuan county in $2006 .{ }^{60}$

\section{NRCMS Improvements between 2006 and 2007}

A customer satisfaction survey carried out among Kazak herders in August 2006, the first year of NRCMS introduction, showed that only 59 per cent found participation worthwhile, 30 per cent were not satisfied and 11 per cent had no opinion. Analysing the reasons for the low satisfaction rate, 72 per cent of those dissatisfied with the scheme mentioned low reimbursement rates for in-patient treatment, 5 per cent found the reimbursement procedures too complicated and 23 per cent gave other reasons. ${ }^{61}$ Furthermore, income and participation are correlated. Households with lower incomes tend not to join NRCMS for financial reasons. In contrast, while the participation rate of high income households is higher, their satisfaction rate is decreasing.

Official reports come to the same conclusion as we do: poor households refuse to join NRCMS because they cannot afford the premiums, and no local subsidies for special schemes of financial medical assistance are available. ${ }^{62}$ The central policy of financial medical assistance (yiliao buzhu 医疗补助), ${ }^{63}$ which provides full coverage or high subsidies to the individual NRCMS contributions of the poor, is not yet implemented in Xinyuan. Only for households of the five guarantees (wubaohu 五保户) is the situation mitigated by full payment of the contribution by the Ministry of Civil Affairs.

In response to the dissatisfaction expressed by participants in 2006, a number of benefit improvements were made for 2007. First, health services provided outside Xinyuan county are now reimbursable, although at a somewhat lower rate. Second, the disposition of the family account for out-patient services has been increased. Originally, of the premium of 25 yuan only 15 yuan was credited to the family account (jiating zhanghu 家庭账户) and could be used for out-patient treatment. Now, the participant's total contribution of 25 yuan is available for

60 Our focus interviews and health survey was also valuable customer feedback to the administrators.

61 Shihezi/Vienna Universities, Xinyuan Pastoral Health Services, p.59.

62 Xinjiang zhengxie (Xinjiang's Political Consultative Conference), "Di 519 hao guanyu jinyibu zuohao woqu xinxing nongmuqu hezuo yiliao shidian gongzuo de jidian jianyi" ("Document No. 519 about suggestions to finish the pilot NRCMS in agricultural and pastoral regions") (30 May 2006), http:// www.xjzx.gov.cn/showcontent.asp?id=4263\&Nclassid=191, accessed 8 July 2008.

63 "Minzhengbu, weishengbu caizhengbu guanyu shishi nongcun yiliao jiuzhu de yijian" ("Suggestions of the Ministry of Civil Affairs, $\mathrm{MoH}$, and MoF about the implementation of the medical financial assistance”), Minfa, No. 58 (18 November 2003), http://www.moh.gov.cn/public/open.aspx?n_id=8365, accessed 12 May 2006; Duckett, Health Financing, p. 56ff. 
out-patient treatment. ${ }^{64}$ Each family member may draw on the total amount available in the family account, and unspent balances are carried forward to the following year. Nevertheless, when looking at the price list for medication or services in health care facilities of Xinyuan county one realizes immediately that the family account for out-patient treatment will quickly be exhausted. ${ }^{65}$ Third, a free annual health check has been introduced, provided that no reimbursement was received during the previous year. ${ }^{66}$ And fourth, as shown in Table 1, reimbursement levels have been increased twice, excess payments decreased and reimbursement ceilings increased once in a 12-month period.

\section{NRCMS claims and financial situation in 2006 and 2007}

The evolution of the NRCMS claims and financial situation is shown in Table $3 .{ }^{67}$ The scheme showed an excess balance of 58.5 per cent (premiums plus state contributions over reimbursements) in 2006 and 24.8 per cent in 2007. The decreasing excess balance is the result of a steep 131.6 per cent increase in the amounts reimbursed, which presumably is due to several factors: the growing acquaintance of participants with the system ${ }^{68}$; a delay of presented claims into the second year; and an accumulation of unattended medical conditions over the years prior to the introduction of the NRCMS, which were diagnosed in 2006 but attended to only in 2007. Reimbursements for hospitalization have increased by 147.6 per cent and for out-patient services by 95.3 per cent. The reimbursement ratio for in- versus out-patient treatment in monetary terms has changed from 2.3:1 in 2006 to 2.9:1 in 2007. The number of claims for hospitalization has increased by 105.1 per cent and for out-patient treatment by 83.5 per cent. The lower percentage increase in out-patient treatment is likely to be the result of the low reimbursement limits where in fact only the accumulated own premium payments are repaid, but is still impressive in absolute numbers. About one half of the participants have on average submitted one additional claim. This shows that the use of medical services under the NRCMS system has substantially grown, implying that the health care situation of the population has improved.

\section{The Role of Health Care Providers}

In contrast to these improvements for the patients, new demands have been placed on the health care providers and their freedom of action has been reduced.

64 Shihezi/Vienna Universities, Xinyuan Pastoral Health Services, p.559 and interview 05/07 para.2; Interview 16/07.

65 E.g. X-rays 11-28 yuan, ultrasound and ECG 6-30 yuan, injections 1-4 yuan, blood/urine analysis 5-13 yuan, registration and examination fees 0.3 and 0.5 yuan. Interview 08/06.

66 Interview 05/07, para.2.

67 Interview 18/07 Q/A 9.

68 Interview 18/07. 
52 The China Quarterly, 201, March 2010, pp. 38-57

Table 3: Development of NRCMS in Xinyuan County, 2006-2007

\begin{tabular}{lrrrrrr}
\hline & 2006 & $\%$ & 2007 & $\begin{array}{c}\text { 2007 versus } \\
\mathbf{2 0 0 6}\end{array}$ & $\begin{array}{c}\text { Growth } \\
\text { in \% }\end{array}$ \\
Premiums + subsidies, $¥$ & $10,080,000$ & & $12,870,000$ & & $+2,790,000$ & +27.7 \\
Reimbursements, $¥$ & $4,180,000$ & 41.5 & $9,680,000$ & 75.2 & $+5,500,000$ & +131.6 \\
$\quad$ for hospitalization, $¥$ & $2,900,000$ & 69.4 & $7,180,000$ & 74.2 & $+4,280,000$ & +147.6 \\
$\quad$ for out-patient, $¥$ & $1,280,000$ & 30.6 & $2,500,000$ & 25.8 & $+1,220,000$ & +95.3 \\
Claims reimbursed, no. & 101,323 & & 186,920 & & $+85,597$ & +84.5 \\
$\quad$ for hospitalization, no. & 4,635 & 4.6 & 9,504 & 5.1 & $+4,869$ & +105.1 \\
$\quad$ for out-patient, no. & 96,688 & 95.4 & 177,416 & 94.9 & $+80,728$ & +83.5 \\
Claims/participant & 0.6 & & 1.2 & & +0.6 & +100.0 \\
& & & & & &
\end{tabular}

The term "health care providers" is used here to refer to those involved with preventive and curative services, essentially physicians and other health care workers. This includes both state-employed and private doctors and nurses. Not included are activities of specialized institutions such as communicable disease control, and maternal and child health, for which a separate organizational setup exists.

\section{Cost containment measures}

The sustainability of NRCMS requires a supply of cheap and trusted health care services as well as well-trained and equipped health clinics, physicians and other health care workers (weishengyuan 卫生员). The state is confronted with an intrinsic contradiction: the providers would like to increase their own economic outcome, but the NRCMS administration must contain costs. The only solution to this problem seems to be to reduce the former decision space of the health care providers. They are forced to respond to the needs of the rural participants of NRCMS, and at the same time their expenses are monitored by the county administration.

First, village doctors are being reorganized under the management of the township health centre and given a monthly payment of 80 yuan for their administrative services to NRCMS (xiangcun weisheng yitihua 乡村卫生服务一体化). Additionally, a stronger link is established between the township hospitals and the county health bureau. The county health bureau selects the director of the township health centre and purchases drugs. ${ }^{69}$

Second, lists of reimbursable medical services and drugs are issued by the Provincial Health Department. These positive lists (zhenliao xiangmu ji yiliao fuwu sheshi xiangmu mulu 诊疗项目及医疗服务设施项目目录; jiben yaopin $m u l u$ 基本药品目录 $)^{70}$ cannot be changed at the county level. ${ }^{71}$

69 "Guanyu nongcun weisheng jigou gaige yu guanli de yijian" ("Suggestions about the reform and management of the rural health care institutions"), Weijifufa, No. 315 (24 December 2002), http://www.moh. gov.cn/jcwsyfybj/zcxx/ncws/1200301060004.htm, accessed 4 August 2003.

70 See Guobanfa, No. 3 (2003).

71 Interview 18/07. 
Third, ranges for in- and out-patient fees have been established by the provincial administration and are controlled by the Price Bureau (wujia ju 物价局). Fees are fixed depending on the complexity of services within these ranges. Higher-level medical institutions tend to charge higher fees, while free practitioners usually charge at the lower end or even below the range to attract patients. ${ }^{72}$ In cases of hospitalization, not more than 7 yuan per night at township hospitals and 9 yuan at county hospitals may be charged. The global patient share in drugs is not to exceed 10 per cent of their total medical expenses, and expenses per participant should not exceed 600 yuan per annum in townships and 1,500 yuan at the county level. All service charges and costs of drugs must be publicized..$^{73}$ Administrators are expected to enforce compliance with these guidelines.

The purpose of these cost containment measures is to protect patients from profit-oriented health centres and to guarantee the financial viability of NRCMS. However, health service providers and in particular country doctors feel that the lists interfere with their professional ethics, provoke conflicts with their patients and unduly reduce their income. In fact, doctors complained about the implementation of these lists, ${ }^{74}$ a reaction which, if not carefully watched, may jeopardize the sustainability of the health insurance scheme from the providers' end.

\section{Compensation for administrative chores}

Doctors have an unpleasant buffer function between NRCMS and patients in cases of dissatisfaction with the medical scheme. It is when they consult the doctor that patients discover the limited reimbursement and lengthy administrative processes of reimbursement. This is especially true when doctors work in mountainous areas where they are the only available contact point.

On the other hand, the integration of health providers into NRCMS, which provides health insurance for a vast majority of the rural population and thereby improves its health spending capability, increases their economic security. For the above reasons, the introduction of NRCMS has been met with mixed feelings by this group, whose overall position must, however, be considered as weakened by the new scheme.

\section{Discussion}

In the past, rural areas have seen excessive and extreme forms of governance, including interference by political campaigns or a total retreat of state action 
after privatization. NRCMS is an example of a departure from these two modes of governance.

One of the most astonishing features of NRCMS is its flexibility in benefit improvements and wide acceptance of the scheme. Local administrators have responded to the needs of enrolled participants but not to the concerns of the doctors. This can be seen from changes introduced or considered in several areas since the inception of the scheme in 2006. These include improvements in reimbursement levels, which became possible following the high excess of contributions over claims reimbursements (58.5 per cent); improved use of the family account; freedom of choice of health services including facilities outside the county household registration; and considerations to unify NRCMS coverage for in- and out-patient treatment (not yet implemented in 2008).

These contemplated or already implemented adjustments are not the result of central directives but of local initiatives. The county health bureau has been empowered to manage the local scheme. In Xinyuan county, the premiums and subsidies remained unchanged between 2006 and 2007. Reimbursement rates, however, increased upon advice from a consultant in health economics at a university in Xinjiang. While our NRCMS customer survey of 2006 revealed a 30 per cent dissatisfaction rate, the number of participants still showed a slight increase possibly because of the benefit improvements introduced for 2007 (Tables 2 and 3). For the NRCMS administrators, enrolment rates were of higher priority than a potential deficit, which had been originally expected for the year $2007 .{ }^{75}$ Indeed, the improved benefit rates did result in many more claims and much higher reimbursements in that year, but the excess balance still showed a solid 24.8 per cent. A further improvement in customer satisfaction and increase in the participation rate may be expected for 2008 .

Our field study in Xinyuan county has revealed quite a number of changes vital for enhancing the situation of rural health care. Primary health care and preventive medicine have been strengthened through free annual check-ups. A first step has also been made towards the central policy goal of poverty reduction through better physical and financial access to health facilities. And furthermore, "responsiveness" in WHO terms has increased, that is, the ability of local health facilities to respond to the requirements and needs of patients.

The central state has finally realized that change is impossible without getting involved at the grassroots level and beginning to subsidize the NRMCS. The document analysis and field study in Xinyuan county confirm that the central government provides financial subsidies without enforcing a strict recentralization of the system. Increased financial subsidies do not correspond to more direct intrusion by the central state bureaucracy. ${ }^{76}$ Soft evaluations and soft targets prevail.

75 Interview 05/07.

76 Susan Whiting, "The cadre evaluation system at the grass roots: the paradox of party rule," in Barry J. Naughton and Dali L.Yang (eds), Holding China Together: Diversity and National Integration in the Post-Deng Era (Cambridge: Cambridge University Press, 2004), pp. 1-25; Yang, Chinese Leviathan, pp. $231 \mathrm{ff}$. 
Instead of direct control by the central state we observed a form of governance in Xinyuan county that is characterized by "responsiveness" of the local administrators to perceptions and expectations of the beneficiaries. In a situation where the interests of the rural population cannot be integrated into a form of top-down rule, where people are not used to articulating their problems and are afraid to speak up, such feedback loops are a rough but effective means to influence state action. Annual enrolment generates high mobilization costs. Annual changes guarantee flexibility but are also difficult to manage. Nevertheless, while in economic terms the approach used for the introduction of NRCMS is not optimal, it establishes self-regulated forms of control from below and makes responsiveness to the demands of the participant peasants possible. Our field studies in Xinyuan show that sceptical households are not forced to join by systemic coercion.

In this form of governance the different levels of state administration play a vital role even if they do not directly interfere in the way NRCMS is run at the local level. This form of co-operation between different levels of the administration is a precondition for implementing the kind of feedback loops necessary for the responsiveness of the scheme.

The central state plays various roles. First, its financial transfers are dependent on the effective number of enrolled participants and their paid premiums as well as on the actually paid co-subsidies from the province and the county. As shown above, without state subsidies the system cannot run properly. However, the central state has to avoid subsidies being taken for granted by lower levels of the administration, and peasant participants not being adequately briefed on the advantages of joining NRCMS. It therefore establishes modes of funding that could be increased yearly, integrated in a system of mutual dependency between rural participants and local CMS administrators.

Second, the central state strengthens the critical role of stakeholders at different levels of state and society. This form of mutual dependency leads to the loci of authority being spread horizontally and vertically. Our case study shows that the implementation of NRCMS needs action at different state levels. We have argued that this need for co-operation is not negative or a sign of administrative malfunctioning, but is functionally necessary. Patients, but also state agencies or local governments, have to recognize the attractiveness and reliability of their mutual commitments. In co-operative systems negotiations enhance co-operation when feedback loops influence the expected added value and the perceived mutual protection of rights and interests. The outcome of these negotiations at the local level defines concrete and sustainable forms of development by forcing local actors into compromise. By the same token, the central state forces the local actors into finding solutions without prescribing the concrete form of the compromise. Instead, it accepts that the compromise between different actors at the local level limits the decision space at the central level. ${ }^{77}$ 
Modes of responsiveness in policy implementation do not have the effect of separating different levels of government from each other, but instead enforce linkages. The mode of governance adopted by NRCMS shows that state and rural society are in the process of overcoming their mutual distance ${ }^{78}$ and are trying out possible ways of co-operating with each other despite existing mistrust and bad historical experiences.

Third, for the time being, the successful integration of responsive modes of governance as a principle does not rely on the articulation of interests in committees or the confirmation of rights through juridical means. Neither does it rely on intact social groups or clans, ${ }^{79}$ but becomes effective by in-built behavioural patterns ("opt-in, re-enrol, or opt-out") ${ }^{80}$ It is an analytically important aspect of our case study that the impact of voluntary participation and administrative fragmentation plays a more important role than any institutional framework. The Administration Committees of the New CMS in Rural and Pastoral Areas (xinxing nongmuqu hezuo yiliao guanli weiyuanhui 新型农牧区合作医疗管理委员会) or the Surveillance Committees (jiandu weiyuanhui 监督委员会) and their suborganizations at the township and village level in principle allow participants to voice their concerns through their representatives in the village CMS committees. ${ }^{81}$ But according to our findings, the actual role of these representatives has so far been of no significance. ${ }^{82}$ Instead we observed a system of checks and balances that works beyond institutional settings.

The principle of annual enrolments prevents peasants from being forced into a state-run and state-dominated health care scheme. Annual re-enrolments increase the pressure on administrators to be flexible in considering structural and procedural adjustments. Participants check the system and develop confidence in its effectiveness because of the power they exert by their annual decision to opt in or out. The right to withdrawal cannot replace the right to voice grievances through local CMS committees, but it strengthens the strategic role of the individual peasant participant inside a system of responsiveness, but outside a system of established democratic organizations.

A considerable number of hurdles are yet to be overcome to make NRCMS sustainable although the inbuilt voluntary nature of the scheme forces cadres and other administrators to make it a success. Hospitals and physicians may find that possible financial losses as a result of NRCMS limits on medical services and drugs will only partly be compensated by an increased overall demand. Pastoralists only confirmed their sustained interest provided the access procedures to health facilities and reimbursement were eased, and the reimbursement

78 Weigelin-Schwiedrzik, Reading Document No. 1.

79 Lily L. Tsai, "The struggle for village public goods provision: informal institutions of accountability in rural China," in Elizabeth J.Perry and Merle Goldman (eds), Grassroots Political Reform in Contemporary China (Cambridge, MA: Harvard University Press, 2007), pp. 117-48.

80 Klotzbücher, Gesundheitswesen, pp. $211 \mathrm{ff}$.

81 Xinyuan County, NRCMS Implementation Guidelines, para. 8.

82 Interview 18/07, para.8. 
ratios for both in- and out-patient services further improved. The local state has in principle agreed to cover any financial shortfalls, but it remains to be seen how much additional funding will be allocated from the central health budget to ensure the long-term sustainability of the scheme.

One major system pitfall remains, which needs further consideration: the initial aim of introducing NRCMS was to prevent peasants from falling into the poverty trap as a consequence of illness. But our fieldwork in Xinyuan county has shown that the financial support from government institutions and the conditions of reimbursement are still insufficient to provide substantial relief. Additional funding is needed to establish higher reimbursement levels and bring about the desired outcome, that is, the improvement of the economic and social status of the rural poor and the abolishment of the medical poverty trap.

\section{Conclusion}

The approach of responsive implementation when introducing NRCMS at the local level could be interpreted as another mode of governance in rural areas. It is particularly attractive to "autonomous" areas such as Xinjiang UAR and the Yili Autonomous Kazak Prefecture, where local particularities suggest approaches based on local initiatives. NRCMS can serve as a new model for increasing central co-payment and a gradual withdrawal of the central state from the traditional top-down (tiao 条) legislation and administration, particularly on issues not requiring nationwide uniformity and cohesion. It provides a range of alternative options to choose from, offers possibilities to derogate from individual provisions, and exempts certain groups of persons or branches of the economy from being covered by the rules. NRCMS operates within a nonhierarchical institutional decision-making structure ("polity"), only guided by centrally established framework regulations. ${ }^{83}$

After years of stalemate in the evolution of rural health care provision, the central state has learnt that excessive intervention provokes resistance and makes change impossible. We believe that a middle-of-the-road solution has now been found through the empowerment of the participants and mutual dependency between the involved state institutions, as well as between health care providers, recipients and administrators inbuilt into the "New Rural Co-operative Medical System.” 